\title{
Pengembangan Integrasi Sistem Unit Pelaksana Penimbangan, Pengujian Kendaraan Bermotor Dan Terminal Pada Tunggal Data Kendaraan
}

Development Of Integrated Weighing Unit Systems, Motor Vehicle Testing And Terminals On Single Vehicle Data

\author{
Ichsan Wasiso $^{* 1}$, Kusrini ${ }^{2}$, Mei P. Kurniawan ${ }^{3}$ \\ ${ }^{1,2,3}$ Business Intelligence; Universitas Amikom Yogyakarta \\ 1, 2, 3 Yogyakarta, Indonesia

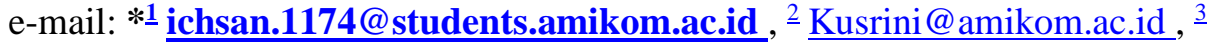 \\ meikurniawan@amikom.ac.id
}

\begin{abstract}
Abstrak - Pembangunan sistem informasi di UPPKB (Unit Pelaksana Penimbangan Kendaraan Bermotor), Terminal Bus, dan PKB (Pengujian Kendaraan Bermotor) dari berbagai penyedia ini telah menghasilkan permasalahan tersendiri. Belum adanya hubungan antara sistem informasi pada data kendaraan yang sangat mungkin dilakukan mengakibatkan terjadinya double entri data kendaraan sehingga mengurangi kemudahan dan kecepatan pengguna dalam melakukan operasional sistem informasi tersebut. Salah satu solusi yang dapat dilakukan untuk mengatasi permasalahan tersebut dengan menggunakan teknologi web service yang terintegrasi. Arsitektur yang digunakan dalam teknologi web service menggunakan metode REST yang mampu menjembatani integrasi data pada masing-masing sistem informasi dari berbagai penyedia yang ada tanpa harus membangun dari awal sebuah sistem baru. Pertukaran data dilakukan dengan menggunakan JSON. Petugas dapat memanfaatkan teknologi tersebut untuk memperoleh data kendaraan secara cepat dan mudah dari sumber data yang telah ditentukan oleh pemerintah. Sebuah server dibutuhkan sebagai tempat pertukaran data kendaraan dari berbagai sistem yang ada. Dengan demikian masing-masing sistem yang sudah ada hanya berhubungan dengan satu server tersebut untuk mendapatkan integrasi data dari berbagai sistem antar daerah. Dengan integrasi sistem ini maka double entri data kendaraan dari beberapa unit dapat dipangkas. Selain menghemat hardisk penyimpanan, integrasi sistem ini dapat mempermudah dan mempercepat proses entri data kendaraan. Pencarian informasi kendaraan menjadi lebih cepat dan lebih mudah.
\end{abstract}

Kata kunci : Integrasi Sistem; JSON; REST; Web Service

\begin{abstract}
The development of information systems at UPPKB (Unit Pelaksana Penimbangan Kendaraan Bermotor), Bus Terminals, and PKB (Pengujian Kendaraan Bermotor) from various providers has resulted in its problems. The absence of a relationship between information systems on vehicle data which is very likely to result in double-entry of vehicle data, thereby reducing the ease and speed of users in carrying out the operation of the information system. One solution that can be done to overcome these problems is by using an integrated web service technology. The architecture used in web service technology uses the REST method which can bridge data integration on each information system from various existing providers without having to build from scratch a new system. Data exchange is done using JSON. Officers can use this technology to obtain vehicle data quickly and easily from data sources that have been determined by the government. A server is needed as a place to exchange vehicle data from various existing systems. Thus, each existing system is only associated with one server to get data integration from various systems between regions. With this system integration, double vehicle data entry from several units can be trimmed. Apart from saving hard disk storage, this system integration can simplify and speed up the vehicle data entry process. Searching for vehicle information is faster and easier.
\end{abstract}

Keywords : JSON; REST; System Integration; Web Service

\section{PENDAHULUAN}

Dalam melaksanakan ketugasan di Terminal Bus, Unit Pelaksana Penimbangan Kendaraan Bermotor (UPPKB), dan Pengujian Kendaraan Bermotor (PKB) masih banyak ditemukan permasalahan antara lain terjadinya proses double entri data, kesulitan dalam proses input data, dan waktu proses input data dan pelaporan belum efisien. Salah satu contoh adalah kesulitan petugas Terminal Bus dan UPPKB untuk mendapatkan informasi habis masa uji di PKB. Petugas Terminal Bus harus melakukan penghentian kendaraan untuk melakukan pemeriksaan habis masa uji dan input data dari 
awal untuk melakukan pendataan kendaraan yang diperiksa.

Untuk dapat mewujudkan peningkatan kecepatan dan kemudahan pelayanan kepada masyarakat tersebut maka sangat penting untuk dilakukan sebuah perubahan inovasi sistem kerja yang selama ini sudah berjalan. Perubahan inovasi sistem kerja ini diharapkan dapat meningkatkan kecepatan dan kemudahan proses pelayanan kepada masyarakat dan petugas sebagai operator sistemnya.

Layanan Web adalah kombinasi dari protokol dan standar terbuka untuk memungkinkan komunikasi antara klien dan server. Ini memberikan interoperabilitas antara aplikasi yang kontras[1]. Representasi status Transfer (REST) dan Simple Object Access Protocol (SOAP) adalah dua layanan web populer yang digunakan sekarang-a-hari. REST adalah gaya arsitektur berbasis, sedangkan SOAP adalah protokol yang mendasarinya. Kedua layanan digunakan untuk menangani komunikasi di world wide web (www).

Oleh karena itu diperlukan sebuah pengembangan sistem kerja yang mampu memangkas waktu dan kegiatan yang tidak efisien tersebut yaitu dengan melakukan Pengembangan Integrasi Sistem Terminal Bus, UPPKB, dan PKB Pada Tunggal Data Kendaraan menggunakan metode Web Service JSON. Pada integrasi ini tidak hanya dilakukan antar sistem saja, akan dibuat sebuah server integrasi yang menjadi pusat integrasi dari masing-masing sistem yang ada. Dengan metode ini proses integrasi akan membutuhkan waktu yang singkat dan mudah dalam implementasinya.

\section{LANDASAN TEORI}

"Web Service adalah aplikasi yang dibuat agar dapat dipanggil dan diakses oleh aplikasi lain melalui internet dengan menggunakan format pertukaran data sebagai format pengiriman pesan" [2],[3]. Web service digunakan sebagai suatu fasilitas yang menyediakan layanan (dalam bentuk informasi atau data) kepada sistem lain, sehingga dapat berinteraksi dengan sistem tersebut melalui layananlayanan yang disediakan[4][5]

Web service menyimpan data informasi dalam format JSON atau XML, sehingga data ini dapat diakses oleh sistem lain walaupun berbeda platform, sistem operasi, dan bahasa pemrograman[6]. Sebuah web service dapat dipanggil oleh aplikasi lain dengan menggunakan bantuan HTTP (HyperText Transfer Protocol). Karena web service menggunakan protokol HTTP, tentu PHP sebagai bahasa pemrograman web menjadi salah satu kekuatan dalam bahasa pemrograman yang mengelola web services

Metode Representational State Transfer (REST) dikembangkan oleh Fielding (2000)[7][8]. REST adalah gaya arsitektur perangkat lunak yang berisi panduan dan praktik terbaik untuk membuat scalable web service[8]. REST merupakan sebuah Batasan set terkoodinasi yang diterapkan pada desain komponen dalam sistem hypermedia terdistribusi yang dapat membuat arsitektur lebih mudah dirawat. REST secara efisien menggunakan HTTP[9][10]. REST didasari oleh empat prinsip utama teknologi, yaitu:

1. Resource identifier through Uniform Resource Identifier (URI)

2. Uniform interface (sumberdaya CRUD menggunakan operasi PUT, GET, POST, dan DELETE).

3. Self-descriptive messages (sumberdaya tidak terikat sehingga dapat mengakses konten HTML, XML, PDF, JPEG, plain text, metadata, dll).

4. Stateful interactions through hyperlinks (bersifat stateless) (Pautasso, 2008).

REST memiliki keuntungan yaitu

1. Support komunikasi stateless.

2. Mudah unutk dipelajari dan diterapkan

3. Penggunaan HTTP secara efeisien.

4. Membutuhkan bandwidth yang kecil pada saat mengirim pesan dalam format JSON (Javascript Object Notation) dan juga dapat digunakan format lain.

5. Untuk keamanan mengugnakan standart HTTP.

6. REST dapat dikonsumsi oleh beberapa client.

7. REST membuat data sebagai sumber daya.

JSON (Javascript Object Notation) adalah format pertukaran data yang ringan, mudah dibaca dan ditulis oleh manusia, serta mudah diterjemahkan dan dibuat (generate) oleh computer, menurut Json Org. JSON(2005)[11][12]. JSON merupakan format teks yang tidak bergantung pada bahasa pemprograman apapun karena menggunakan gaya bahasa yang umum digunakan oleh 
programmer keluarga $\mathrm{C}$ termasuk $\mathrm{C}, \mathrm{C}++, \mathrm{C \#}$, Java, JavaScript, Perl, Python dll[13]. Oleh karena sifat-sifat tersebut, menjadikan JSON ideal sebagai bahasa pertukaran data.

Arsitektur client - server merupakan suatu desain dari sebuah aplikasi yang terdiri dari client dan server di mana saling berkomunikasi satu sama lain ketika mengakses server dalam satu jaringan[10]. Client sendiri merupakan mesin pengguna yang menyediakan user interface dan local processing di mana melakukan suatu permintaan data atau layanan ke server. Sedangkan server merupakan mesin yang menyediakan data atau layanan yang diminta oleh client.

Dalam penelitian ini menggunakan tiga objek sistem yang akan di intergrasikan. Pertama adalah terminal, pengertian terminal berdasarkan Peraturan Menteri Perhubungan No 40 Tahun 2015 Tentang Standart Pelayanan Penyelenggaraan Terminal Penumpang Angkutan Jalan[14] :

1. Terminal adalah pangkalan kendaraan bermotor umum yang digunakan untuk mengatur kedatangan dan keberangkatan, menaikkan dan menurunkan orang atau barang, serta perpindahan moda angkutan.

2. Standart pelayanan adalah tolok ukur yang dipergunakan sebagai pedoman penyelenggaraan pelayanan dan acuan penilaian kualitas pelayanan sebagai kewajiban dan janji penyelenggara kepada masyarakat dalam rangka pelayanan yang berkualitas, cepat, mudah, terjangkau, dan terukur.

3. Kehandalan atau keteraturan diterminal penumpang angkutan jalan sebagaimana dimaksud pada ayat (1) huruf $\mathrm{c}$, meliputi

a. Jadwal kedatangan dan keberangkatan kendaraan serta besaran tarif kendaraan bermotor umum beserta realisasi jadwal secara tertulis;

b. Jadwal kendaraan umum dalam trayek lanjutan dan kendaraan umum tidak dalam trayek lanjutan beserta realisasi jadwal secara tertulis;

c. Loket penjualan tiket;

d. Kantor penyelenggara terminal, ruang kendali dan manajemen sistem informasi terminal;

e. Petugas operasional terminal;
Objek yang kedua adalah Pengujian Kendaraan bermotor merupakan tempat yang berdasarkan Peraturan Menteri Perhubungan Republik Indonesia Nomor Pm 133 Tahun 2015 Tentang Pengujian Berkala Kendaraan Bermotor[15].

1. Kendaraan bermotor adalah setiap kendaraan yang digerakkan oleh peralatan mekanik berupa mesin selain kendaraan yang berjalan di atas rel.

2. Pengujian kendaraan bermotor adalah serangkaian kegiatan menguji dan/atau memeriksa bagian atau komponen kendaraan bermotor, kereta gandengan, dan kereta tempelan dalam rangka pemenuhan terhadap persyaratan teknis dan laik jalan.

3. Unit Pelaksana Uji Berkala Kendaraan Bermotor adalah unit tempat dilaksanakannya kegiatan uji berkala kendaraan bermotor.

4. Penguji kendaraan bermotor adalah petugas yang diberi tugas, tanggung jawab, wewenang, dan hak secara penuh oleh pejabat yang berwenang untuk melakukan pengujian berkala kendaraan bermotor.

Untuk mencapai tujuan sebagaimana dimaksud dalam Pasal 2, penyelenggaraan pengujian berkala kendaraan bermotor harus memenuhi persyaratan salah satunya adalah harus tersedia sistem informasi yang berisi kemudahan dan kejelasan bagi pemohon pengujian berkala dan terintegrasi secara nasional. Setiap Unit Pelaksana Uji Berkala Kendaraan Bermotor harus menyelenggarakan sistem informasi pelaksanaan uji berkala kendaraan bermotor.

Sistem Informasi sebagaimana dimaksud pada ayat (1) harus diintegrasikan dengan pusat data Direktorat Jenderal, Unit Pelaksana Uji Berkala Kendaraan Bermotor lainnya, Dinas Perhubungan Provinsi setempat, Unit Pelaksana Penimbangan Kendaraan Bermotor, Terminal Angkutan Penumpang, dan Terminal Angkutan Barang melalui Direktorat Jenderal. Pusat data berhak dan wajib memantau kegiatan uji berkala di seluruh Indonesia secara online dan realtime. Data dan informasi pengujian kendaraan bermotor dipergunakan untuk pembinaan, pengawasan dan penelitian dalam rangka pengembangan kebijakan pengujian kendaraan bermotor.

Objek berikutnya adalah Unit Pelaksana Penimbangan Kendaraan Bermotor, 
berdasarkan Peraturan Menteri Perhubungan No 134 Tahun 2015 yang dimaksud Unit Pelaksana Penimbangan Kendaraan Bermotor adalah unit kerja dibawah Kementerian Perhubungan yang melaksanakan tugas pengawasan muatan barang dengan menggunakan alat penimbangan yang dipasang secara tetap pada lokasi tertentu. Salah satu kewajiban penyelenggaraan UPPKB adalah menyediakan sistem informasi yang dapat mengelola pelaksanaan hasil kegiatan[16]. Sistem informasi sebagaimana dimaksud dalam pasal 28 ayat (2) paling sedikit memuat :

1. Data kendaraan dan perusahaan angkutan barang;

2. Data jenis muatan;

3. Data berat muatan;

4. Data asal tujuan muatan; dan

5. Data pelanggaran

Sistem informasi sebagaimana dimaksud dalam pasal 28 ayat (2) didukung dengan alat penimbangan yang memiliki kemampuan paling sedikit :

1. Melaksanakan proses penimbangan kendaraan bermotor atas perintah operator komputer penimbangan dan mengambil kendaraan yang ditimbang;

2. Melaksanakan proses penimbangan kendaraan secara otomatis;

3. Memiliki kemampuan identifikasi data kendaraan dengan menggunakan data yang telah dimiliki oleh Direktorat Jenderal Perhubungan Darat.

4. Memiliki kemampuan deteksi dimensi kendaraan;

5. Melaksanakan proses penindakan secara otomatis kepada kendaraan yang melanggar;

6. Memiliki kemampuan evaluasi data baik yang ditampilkan secara matrik maupun grafik; dan

7. Memiliki kemampuan untuk mengirim data penimbangan kepada Direktorat Jenderal

\section{METODE}

Pengembangan integrasi sistem UPPKB, Terminal Bus, dan PKB dilakukan menggunakan metode RESTfull web service yang mana RESTfull web service akan digunakan sebagai server untuk melayani data request dari ketiga sistem yang diintegrasikan.

Gambar 1 menunjukkan bagaimana alur penelitian yang dilakukan dalam pengembangan sistem terintegrasi dari ketiga sistem yang sudah ada dan menjelaskan bahwa setelah dilakukan analisa data untuk menentukan kebutuhan integrasi data kemudian dibuat sebuah server yang digunakan sebagai tempat tunggal integrasi sistem tersebut. Selanjutnya dibuat web service yang akan digunakan untuk menerima perintah integrasi sistem. Langkah selanjutnya akan dilakukan pengujian integrasi sistem untuk data-data yang sudah ditentukan pada analisa data integrasi sistem.

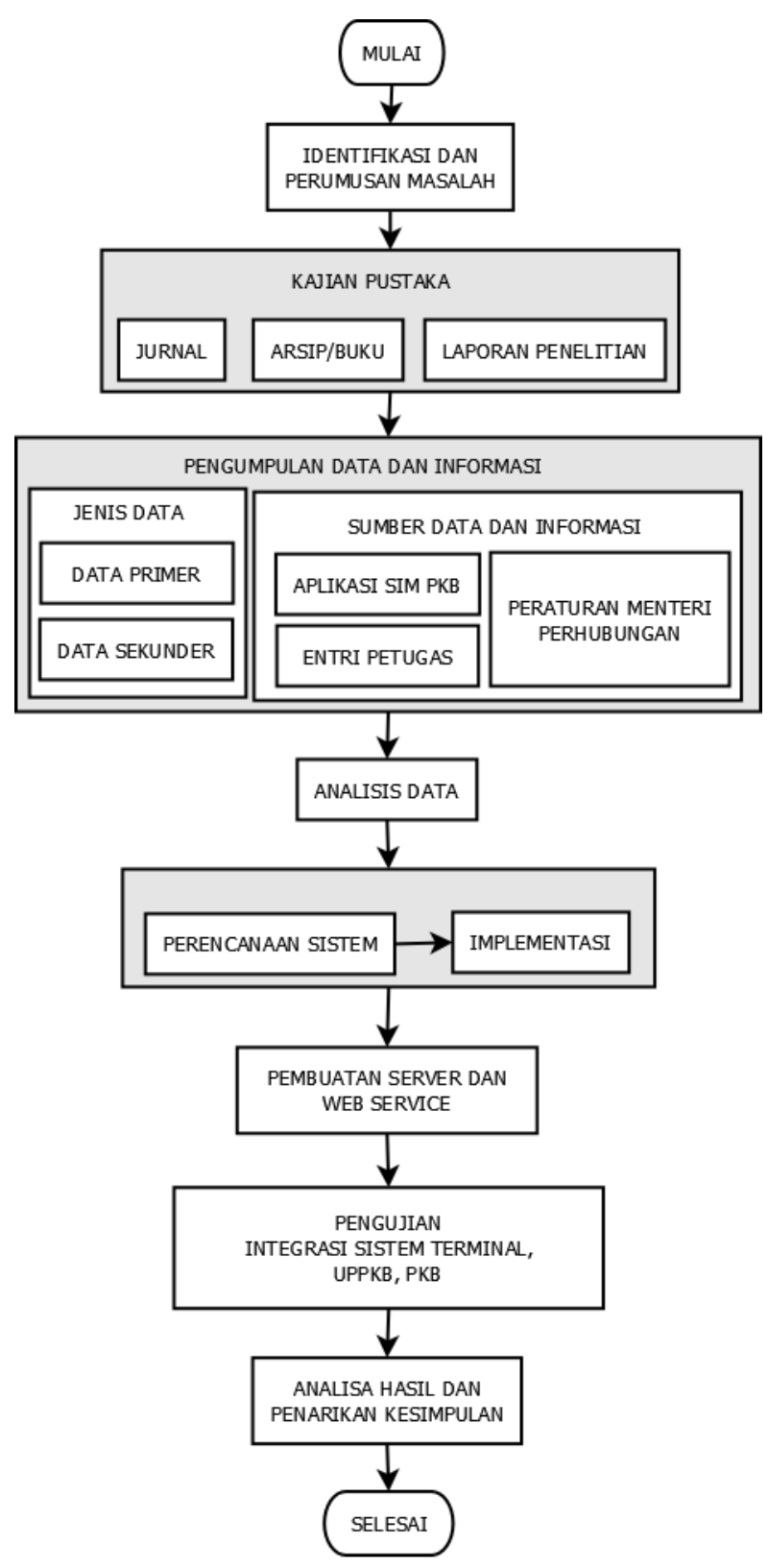

Gambar 1. Alur Penelitian

\section{HASIL DAN PEMBAHASAN}

\section{A. Pengumpulan Data}

Dalam proses pengumpulan data kendaraan terdapat beberapa metode yang digunakan antara lain : 
a. Entri data kendaraan di PKB dilakukan oleh petugas dishub dengan memasukkan data kendaraan pada form yang telah disediakan di aplikasi secara online;

b. Entri data di UPPKB dilakukan oleh petugas Kemenhub dengan memasukkan data pada form yang telah disediakan di aplikasi secara online;

c. Entri data di Terminal Bus Tipe A dilakukan oleh petugas Kemenhub dengan memasukkan data pada form yang telah disediakan di aplikasi secara online.

d. Dalam proses entri data petugas dapat menggunakan perangkat seperti tablet, komputer, laptop, maupun smartphone yang dilengkapi dengan jaringan internet.

Dalam melakukan penelitian ini diperlukan beberapa data pendukung antara lain :

1. Data pemilik kendaraan

2. Data kendaraan;

3. Data pengujian kendaraan;

4. Data pelanggaran;

5. Data perusahaan angkutan;

6. Data merk kendaraan;

7. Data jenis kendaraan;

8. Data klasifikasi kendaraan;

9. Data kabupaten atau kota;

10. Data bahan bakar;

11. Data bahan bak karoseri;

12. Data konfigurasi sumbu;

13. Data kelas jalan;

14. Data pasal pelanggaran

B. Analisis Data

Dalam penelitian ini dibutuhkan beberapa tahapan dalam melakukan analisis data antara lain :

1. Melakukan analisa data kendaraan yang dibutuhkan oleh Terminal Bus, UPPKB, dan PKB untuk menentukan data-data yang akan dilakukan integrasi.

2. Menentukan kata kunci untuk mendapatkan informasi kendaraan. Kata kunci yang akan digunakan antara lain :

3. Membuat kata kunci untuk menerima integrasi data dari sistem eksternal.

Untuk dapat mendukung kegiatan penelitian diperlukan beberapa perangkat pendukung antara lain :

1. Server digunakan sebagai tempat menjalankan dan penyimpanan data tunggal kendaraan.

2. Komputer atau laptop digunakan oleh peneliti untuk melakukan entri data dan analisis data kendaraan.

3. Jaringan internet digunakan untuk menghubungkan antara Terminal Bus, UPPKB, dan PKB dari berbagai lokasi.

\section{Implementasi}

Pada integrase system ini akan dilakukan dengan membuat sebuah server yang akan menjadi tempat untuk pertukaran data dari berbagai system yang ada. Masing-masing client dilakukan pendataan untuk link api yang digunakan. Dengan begitu server dapat menerima dan mengirimkan balasan permintaan data sesuai kebutuhan integrasi sistem. 


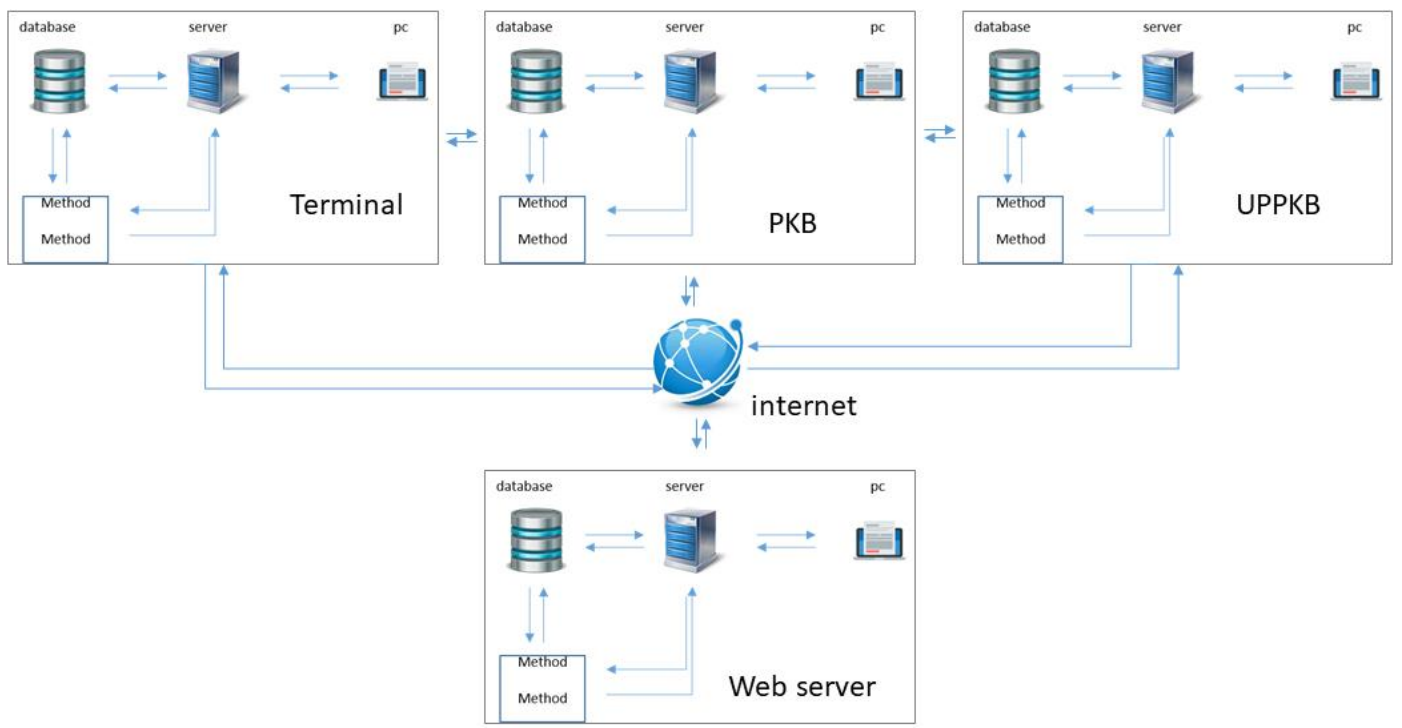

Gambar 2. Arsitektur Jaringan

Dalam membuat sistem terintegrasi dari tiga sistem yang sudah ada diperlukan sebuah server yang digunakan untuk menjadi tempat pusat integrasi data dari masing - masing database sistem yang ada pada sistem informasi terminal, sistem informasi $\mathrm{PKB}$ dan sistem informasi UPPKB. Gambar 2 menunjukkan siklus alur data sistem yang terintegrasi dengan web server dengan contoh kasus misalkan dari terminal membutuhkan data, sistem informasi terminal akan mengajukan permintaan ke web server (server pusat), selanjutnya server pusat akan merespon dan melakukan pencarian data yang sesuai dengan kebutuhan pada server PKB dan UPPKB. Setelah itu server PKB dan UPPKB akan memberikan respon data didapatkan atau tidak, dan respon tersebut akan disampaikan secara langsung ke sistem terminal yang melakukan permintaan data bahwa data yang diminta ada atau tidak. Proses tersebut berlaku dengan sistem PKB dan sistem UPPKB sehingga hubungan masing - masing sistem berlangsung ke web server (server pusat), tidak langsung ke server masing - masing unit.

Web Sevice dibangun menggunakan bahasa pemrograman php yang berfungsi untuk melayani permintaan data dari sistem ke server yang terintegrasi. data request dikirimkan oleh client dalam format JSON. gambar 3 , gambar 4 merupakan sebagian Source Code yang di gunakan pada web service.

$\begin{array}{ll}\text { ?php } & \\ & \text { \$kunci = \$tahun; } \\ & \text { \$kategori = 'tgl'; }\end{array}$

\section{\$modele = 'Tahun'; \\ $\$$ no $=0$;}

\$kunci $=$ str_replace(" ", "\%20", \$kunci);

\$json_url =

'http://terminal.bptdwilx.id/knoynom/c

ek_sidang2.php?kategori=' .\$kategori.' '\&

kunci=' .\$kunci. ' \&modele=' . \$modele. ' ';

$\$ c h=$ curl_init (\$json_url);

\$options = array (

CURLOPT_RETURNTRANSFER $\Rightarrow$ true,

CURLOPT_HTTPHEADER $\Rightarrow$ array ('Content-

type: application/json'),

);

curl_setopt_array (\$ch, \$options); //

setting cur $\bar{l}$ options

$\$$ result = curl_exec $(\$ c h) ; / /$ getting

json result string

\$decode $=$ json_decode (\$result, true) ;

if (is_array ( $\$$ decode $))\{$

foreach (\$decode['tipe'] as \$row) \{

$\$$ no++;

?>

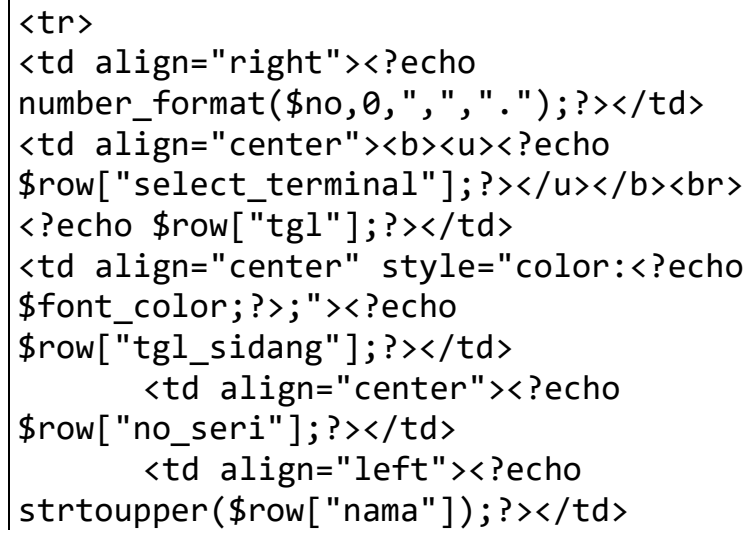




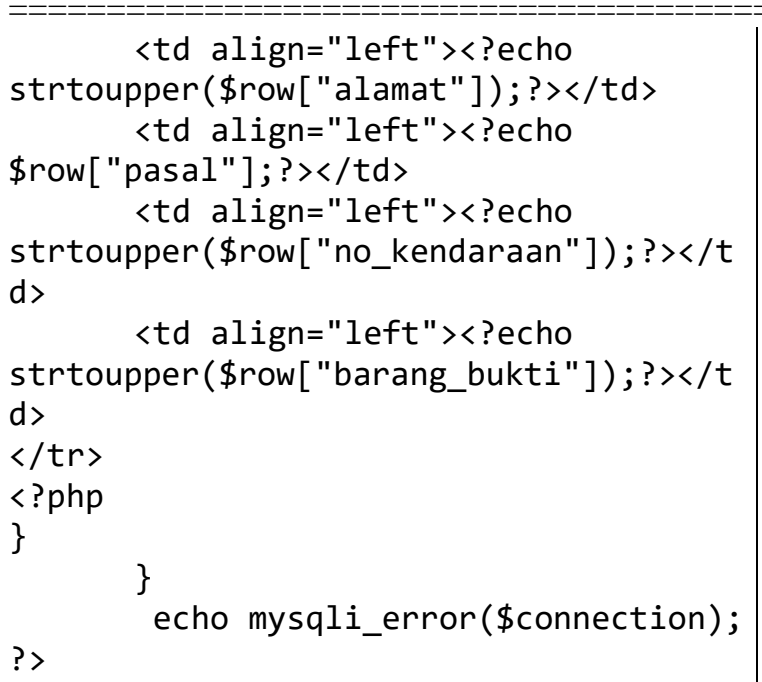

Gambar 3. Permintaan Data Sidang.

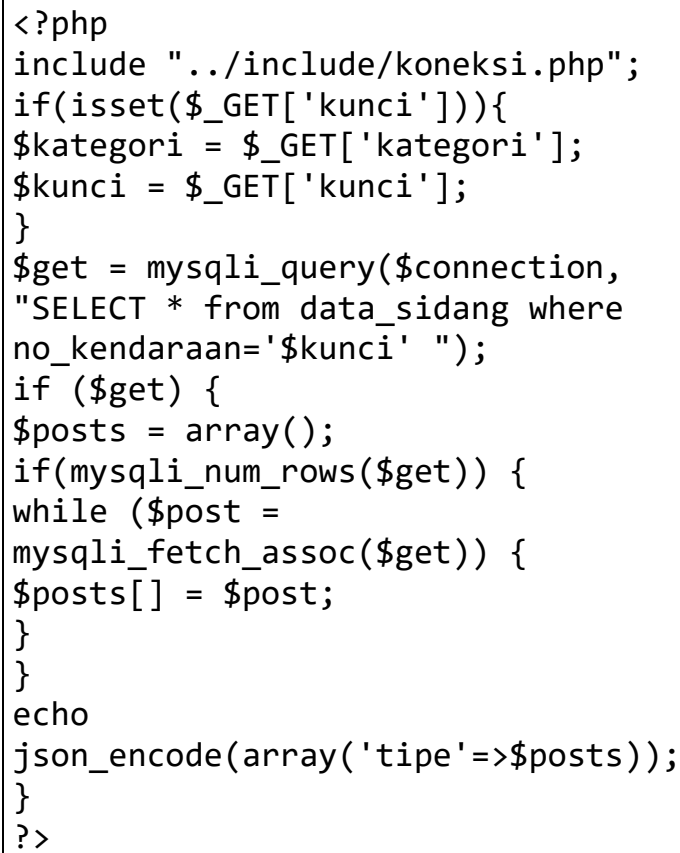

Gambar 4.Pemrosesan Data Integrasi

\section{Pengujian Sistem}

Pengujian web service gambar 5 dan gambar 6 dilakukan dengan melakukan permintaan data ke web service (server pusat). Pada saat dilakukan inspeksi dan ditemukan kendaraan angkutan umum yang tidak memenuhi persyaratan layak jalan, salah satunya uji KIR. Maka petugas dapat melakukan pengecekan apakah kendaraan tersebut sudah memperbaharui ato belum. Jika belum dan surat KIR telah melebihi jatuh tempo maka petugas dapat memberikan sanksi sesuai aturan. Gambar $\underline{6}$ merupakan data yang berisi diskripsi sidang yang harus dijalani oleh pelanggar. Dalam gambar 6 terlihat tanggal sidang, tempat sidang, pelanggaran dan jaminan pelanggaran.
Dengan adanya integrasi sistem akan mempermudah petugas dalam melakukan mengecekkan data kendaraan.

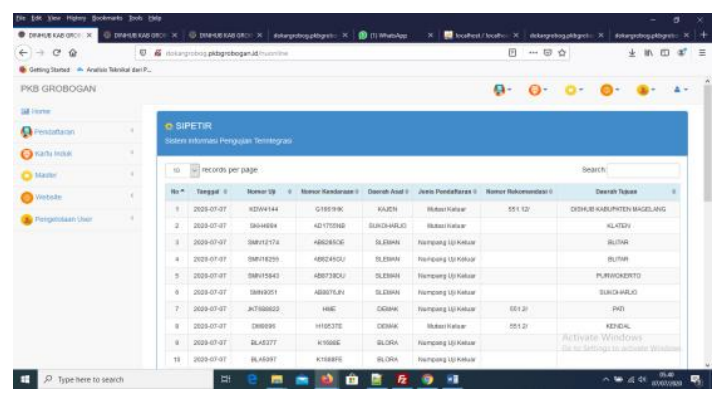

Gambar 5.Integrasi Sistem PKB.

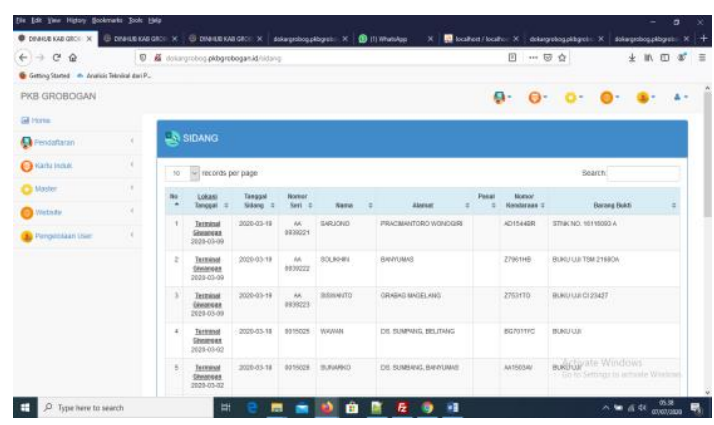

Gambar 6. Integrasi Sistem Sidang.

\section{KESIMPULAN}

Penelitian ini telah berhasil membangun sistem integrasi data antar sistem informasi yaitu sistem Terminal Bus, Sistem Unit Pelaksana Penimbangan Kendaraan Bermotor (UPPKB), dan Sistem Pengujian Kendaraan Bermotor (PKB). Integrasi data dibangun menggunakan RESTfull web service, bahasa pemrograman PHP dan database MySQL. Akses web service dilakukan dengan mengirimkan data dalam format JSON. Integrasi system yang telah dilakukan mampu untuk mempermudah proses input data kendaraan dan mempercepat proses pencarian informasi kendaraan yang dibutuhkan. Selain itu dengan menggunakan sistem integrasi ini tidak ada lagi double entri data kendaraan yang dilakukan.

\section{DAFTAR PUSTAKA}

[1] A. Soni and V. Ranga, "API features individualizing of web services: REST and SOAP," Int. J. Innov. Technol. Explor. Eng., vol. 8, no. 9 Special Issue, pp. 664-671, 2019, doi: 
10.35940/ijitee.I1107.0789S19.

[2]

M. Yazdi, "IMPLEMENTASI WEBSERVICE PADA SISTEM PELAYANAN PERIJINAN TERPADU SATU ATAP DI PEMERINTAH KOTA PALU Mohammad," in Seminar Nasional Teknologi Informasi \& Komunikasi Terapan, 2012, pp. 450457.

[3] S. Sibagariang, "Penerapan Web Service Pada Perpustakaan Berbasis Android," J. Maharjana Inf., vol. 1, no. 2, pp. 811, 2016, [Online]. Available: http://ejournal.sari-

mutiara.ac.id/index.php/7/article/view/1 72.

[4] L. N. Asiyah, M. P. T. Sulistyanto, and A. Aziz, "Penerapan Restful Web Service Untuk Optimalisasi Kecepatan Akses Pada Aplikasi Berbasis Android," JOINTECS (Journal Inf. Technol. Comput. Sci., vol. 5, no. 2, p. 129, 2020, doi: 10.31328/jointecs.v5i2.1260.

[5] M. I. Perkasa and E. B. Setiawan, "Pembangunan Web Service Data Masyarakat Menggunakan REST API dengan Access Token," J. Ultim. Comput., vol. 10, no. 1, pp. 19-26, 2018, doi: 10.31937/sk.v10i1.838.

[6] R. Perwira and B. Santosa, "Implementasi Web Service pada Integrasi Data Akademik dengan Replika Pangkalan Data Dikti," Telematika, vol. 14, no. 01, pp. 1-11, 2017, doi:

10.31315/telematika.v14i01.1962.

[7] T. Andriyanto and R. Indriati, "RESTFul Web Service Untuk Integrasi Data Antar Sistem Informasi," J. Sains dan Inform., vol. 3, no. 2, p. 116, 2017, doi: 10.34128/jsi.v3i2.111.

[8] F. R. Rohman, A. A. Soebroto, and A. P. Kharisma, "Pengembangan Perangkat Lunak Aplikasi Monitoring Klimatologi Menggunakan Metode RESTful Web service Berbasis Android ( Studi Kasus : Stasiun Klimatologi Karangploso Malang )," Pengemb. Teknol. Inf. dan Ilmu Komput., vol. 2, no. 6, pp. 20172023, 2018.

[9] F. N. Rofiq and A. Susanto, "Implementasi RESTful Web Service untuk Sistem Penghitungan Suara Secara Cepat pada Pilkada," Eksplora Inform., vol. 6, no. 2, pp. 159-168, 2017, [Online]. Available: https://eksplora.stikom-

bali.ac.id/index.php/eksplora/article/vie w/116/97.

[10] R. Abilio, "Systems Integration Using Web Services, REST and SOAP: A Practical Report," sistemas, vol. 19, no. June, pp. 34-41, 2017, [Online]. Available:

http://www.fsma.edu.br/si/sistemas.html 34

[11] A. Wijanarko, "Integrasi Data SID dan SMS Gateway menggunakan Web Service untuk Layanan Desa Blank Spot Area Data," J. Tek. Inform. dan Sist. Inf., vol. 5, no. 2, pp. 159-168, 2019, doi: 10.28932/jutisi.v5i2.1597.

[12] R. Gunawan and A. Rahmatulloh, "JSON Web Token (JWT) untuk Authentication pada Interoperabilitas Arsitektur berbasis RESTful Web Service," J. Edukasi dan Penelit. Inform., vol. 5, no. 1, p. 74, 2019, doi: 10.26418/jp.v5i1.27232.

[13] E. W. Kenali and H. Fathoni, "Desain Dan Implementasi Service Provider Berbasis Web Services Push Pangkalan Data Perguruan Tinggi Pada Sistem Informasi Akademik Politeknik Negeri Lampung," in Seminar Bisnis \& Teknologi 2014 IBI Darmajaya, 2014, pp. 15-16.

[14] Kementerian Perhubungan, Peraturan Mentri Perhubungan Nomor 40 Tahun 2015 Tentang Penyelenggaraan Terminal Penumpang Angkutan Jalan. indonesia, 2015.

[15] Kementerian Perhubungan, Peraturan Menteri Perhubungan Republik Indonesia Nomor PM 133 Tahun 2015 tentang Pengujian Berkala Kendaraan Bermotor. Indonesia, 2015.

[16] Kementerian Perhubungan, Peraturan Menteri Perhubungan Republik Indonesia Nomor PM 134 Tahun 2015 tentang Penyelenggaraan Penimbangan Kendaraan Bermotor di Jalan. Indonesia, 2015. 